Document downloaded from:

http://hdl.handle.net/10251/179789

This paper must be cited as:

Doostkami, H.; Roig-Flores, M.; Negrini, A.; Mezquida-Alcaraz, EJ.; Serna Ros, P. (2020). Evaluation of the Self-healing Capability of Ultra-High-Performance Fiber-Reinforced Concrete with Nano-Particles and Crystalline Admixtures by Means of Permeability. Springer. 489-499. https://doi.org/10.1007/978-3-030-58482-5_45

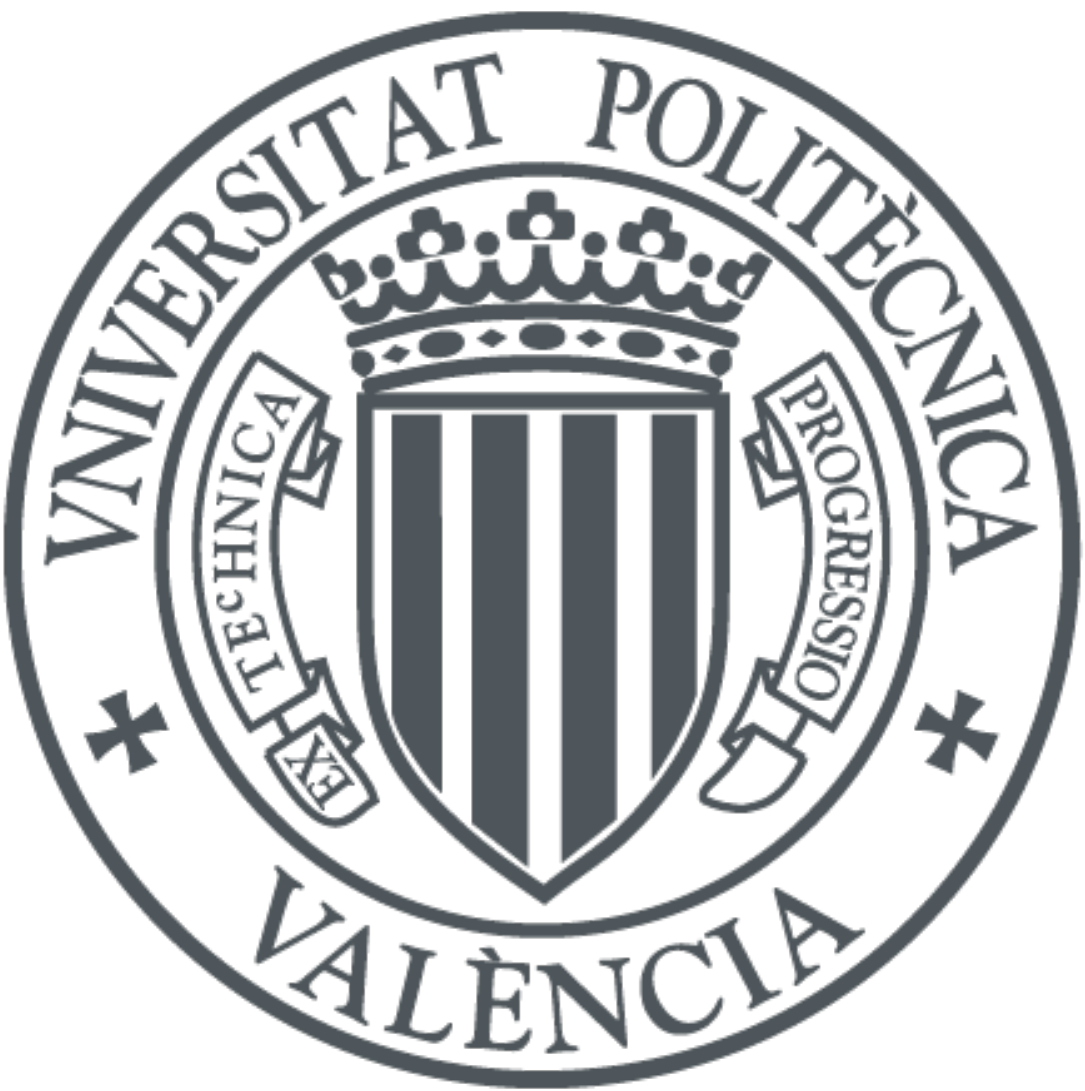

The final publication is available at

https://doi.org/10.1007/978-3-030-58482-5_45

Copyright Springer

Additional Information 


\title{
EVALUATION OF THE SELF-HEALING CAPABILITY OF ULTRA-HIGH-PERFORMANCE FIBER-REINFORCED CONCRETE WITH NANO-PARTICLES AND CRYSTALLINE ADMIXTURES BY MEANS OF PERMEABILITY
}

\author{
Hesam Doostkami $^{(1)}{ }^{*}$, Marta Roig-Flores $^{(1)}$, Alberto Negrini ${ }^{(1)}$, Eduardo J. Mezquida-Alcaraz ${ }^{(1)}$ \\ and Pedro Serna ${ }^{(1)}$ \\ (1) Universitat Politècnica de València, Instituto de Ciencia y Tecnología del Hormigón, Valencia, Spain \\ *Corresponding author: hedoo@doctor.upv.es
}

\begin{abstract}
Self-healing is the capability of a material to repair its damage autonomously. Ultra-High-Performance Fiber Reinforced Concrete (UHPFRC) has potentially higher self-healing properties than conventional concrete because of its lower water/binder content and controlled microcracking due to the high fiber content. This work uses a novel methodology based on the permeability to evaluate autogenous selfhealing of UHPFRC and enhanced self-healing, incorporating several additions. To this purpose, one UHPFRC was selected and modified to include alumina nanofibers in $0.25 \%$ by the cement weight, nanocellulose (nanocrystals and nanofibers), in a dosage of $0.15 \%$ by the cement weight, and $0.8-1.6 \%$ of a crystalline admixture. The results obtained show that the methodology proposed allows the evaluation of the self-healing capability of different families of concrete mixes that suffered a similar level of damage using permeability tests adapted to the specific properties of UHPFRC.
\end{abstract}

KEYWORDS: Ultra High-Performance Fiber Reinforced Concrete, self-healing, crystalline admixtures, nanocellulose, alumina nanofibers.

\section{INTRODUCTION}

The presence of small cracks is unavoidable in reinforced concrete due to the brittleness of its cementitious matrix. Cracks can be produced by several causes such as mechanical loads, drying shrinkage, external loads, or thermal actions as freezing and thawing cycles [1]. Generally, small cracks are not relevant from the structural point of view but can reduce the durability of the structure through the entrance of water or aggressive agents, such as chlorides. This problem can be especially relevant in structures with expensive maintenance or repair, such as marine off-shore structures [2].

Concrete can heal its cracks autogenously by continuing hydration and carbonation of its particles [3]. For these reactions, the presence of water is necessary to hydrate the un-hydrated cement particles and to produce the precipitation of carbonate calcium crystals as a result of the reaction between calcium and carbonate ions and carbon dioxide [4]. Whereas cracks under $300 \mu \mathrm{m}$ are considered not to affect the mechanical properties of reinforced concrete and are accepted in codes such as CEB_FIP code,1990 
Eurocode 2,1992 or BS 8110-1,1997, they can decrease the durability and service life of concrete [4]. Additionally, some structures will require to be watertight, and the presence of small cracks should be completely minimized. It has been reported that the shape, tortuosity, and direction of cracks affect the permeability of concrete [5]. While crack openings until $50 \mu \mathrm{m}$ have a negligible effect on water permeability, cracks around $200 \mu \mathrm{m}$ increase water permeability [6].

In addition to the entrance of water, the penetration of chlorides is also of interest due to their role in corrosion of steel reinforcement. It has been reported [7] that small cracks of sizes until $60 \mu \mathrm{m}$ can fully heal in terms of resistance to chloride diffusion, while for wider crack widths, the resistance produced by healing will only be partial. The age of the healed crack was reported [8] as relevant for cracks $<60$ $\mu \mathrm{m}$, in terms of protection to chloride diffusion, while for larger cracks, it was not critical.

Ultra High-Performance Fiber Reinforced Concrete (UHPFRC) is a recently developed concrete with high durability performance [9]. UHPFRC allows increasing deformability and reduction of brittleness due to the improvement in the tensile properties and achievement of post-cracking behavior. This behavior is obtained thanks to the presence of fibers, optimizing the size distribution of its particles, reducing water/binder ratio, and including silica fume. UHPFRC has a high compacity, low permeability and capillarity absorption, and better control on crack opening [10]. Additionally, low water/binder ratios in the range of UHPC-UHPFRC can improve autogenous healing capacities due to the high percentage of un-hydrated cement particles [11]. Studies performed on High-Performance Concrete (HPC) and High-Performance Fiber-Reinforced Concrete (HPFRC) [12], analyzed the efficiency of autogenous healing due to the presence of fibers under monotonic loading. Their results showed that healed specimens with fibers had a lower water permeability and higher healing ratios compared to healed samples without fibers.

One of the most common additives used to promote self-healing of concrete is Crystalline Admixtures (CA). Some authors compared the self-healing efficiency samples in several conditions, [13] studying the effect of CA combined or not with calcium sulfoaluminate expansive additive. Their results showed better crack closure for samples submerged in water and measured higher content of $\mathrm{Ca}^{2+}$ and higher $\mathrm{pH}$ in those samples with CA, which favors calcium carbonate precipitation. These results are consistent with those obtained by [14],[15], which showed the critical effect of water presence for the reactions, obtaining healing ratios up to $95-98 \%$ in water immersion conditions, measured through improvements in water tightness, even though the improvement compared with their reference specimens was only scarce. Other authors [16] reported that the presence of CA could speed up healing and are highly effective in the restoration of stiffness and load-bearing capacity. The effect of CA on the self-healing of high-performance fiber-reinforced concrete is potentially more critical compared to normal strength concrete due to their higher binder content and lower $\mathrm{w} / \mathrm{b}$ ration, which favors delayed hydration reactions [17]. Some studies focusing on high salinity conditions [18],[19], showed that CA promoted better strength recovery, higher crack closure and a positive effect on reducing chloride penetration, even in air-exposure [19].

In addition to CA, other materials may improve concrete healing properties. This work studies the selfhealing capability of a UHPFRC upgraded to incorporate CA, alumina nanofibers (ANF), and nanocellulose fibers and crystals (CNF, CNC respectively), using water permeability tests adapted to the properties of UHPFRC, based on the penetration of chlorides through water inside the cracks.

\section{MATERIALS AND METHODOLOGY}

\subsection{Materials}

An Ultra High-Performance Fiber Reinforcement Concrete (UHPFRC, labeled as C3) was prepared as the reference concrete. This concrete mix was modified to include crystalline admixtures and nanomaterials to study the effect of these materials on the self-healing properties. 
The materials used in this study include CEM I 42.5 R-SR5 from LAFARGE, undensified silica fume from Elkem as part of the binder. The aggregates used are fine silica sand $(0 / 0.5 \mathrm{~mm})$, medium-size silica sand $(0 / 1.6 \mathrm{~mm})$, and silica flour Quarzfin U-S 500 from Sibelco. The mix incorporated short straight-shaped steel fibres 13/0.2 (length $13 \mathrm{~mm}, \Phi=0.2 \mathrm{~mm}, 1_{\mathrm{f}} / \mathrm{d}_{\mathrm{f}}=13 / 0.2=65$, tensile strength $>$ $2000 \mathrm{MPa}$ ), to guarantee ductility and multiple micro-cracking. Superplasticizer Sika Viscocrete 20HE was used to obtain the self-compacting behavior of this concrete. The crystalline admixture was provided by PENETRON. Nanocellulose was provided by API; the materials used are cellulose nanocrystals $(C N C)$ from API $(\Phi=4-5 \mathrm{~nm}, \mathrm{~L} 50-500 \mathrm{~nm})$ and cellulose nanofibers $(C N F)(\Phi=3-4 \mathrm{~nm} \mathrm{~L}$ 400-700nm). Alumina nano-fibres (ANF) were obtained from NAFEN ( $\Phi=4-11 \mathrm{~nm}, \mathrm{~L} 100-900 \mathrm{~nm})$. Table 1 shows the seven concrete mixes, their composition and code used for this work.

Table 1. Mix designs of the seven UHPFRCs prepared.

\begin{tabular}{|c|c|c|c|c|c|c|c|}
\hline$\left(\mathrm{kg} / \mathrm{m}^{3}\right)$ & C3 & C31 & C32 & C33 & C34 & C35 & C36 \\
\hline Cement I 42.5 R-SR & 800 & 800 & 800 & 800 & 800 & 800 & 800 \\
\hline Silica fume & 175 & 175 & 175 & 175 & 175 & 175 & 175 \\
\hline Water & 160 & 160 & 165 & 165 & 180 & 180 & 180 \\
\hline$w / c$ & 0.200 & 0.200 & 0.206 & 0.206 & 0.225 & 0.225 & 0.225 \\
\hline$w / b$ & 0.164 & 0.164 & 0.169 & 0.169 & 0.185 & 0.185 & 0.185 \\
\hline Silica sand $-0 / 1.6 \mathrm{~mm}$ & 565 & 565 & 565 & 565 & 565 & 565 & 565 \\
\hline Silica sand $-0 / 0.5 \mathrm{~mm}$ & 302 & 302 & 302 & 302 & 302 & 302 & 302 \\
\hline Silica flour $-<50 \mathrm{~m}$ & 225 & 225 & 225 & 225 & 225 & 225 & 225 \\
\hline Short steel fibres (13/0.2) & 160 & 160 & 160 & 160 & 160 & 160 & 160 \\
\hline Superplasticizer & 30 & 30 & 30 & 30 & 30 & 30 & 30 \\
\hline $\mathbf{C A}$ & - & 7.8 & 7.8 & 15.6 & - & 7.8 & 7.8 \\
\hline ANF (solid content) & - & - & 2.44 & 2.44 & - & - & - \\
\hline CNC (solid content) & - & - & - & - & 0.73 & 1.46 & 0.73 \\
\hline CNF (solid content) & & & & & 0.73 & - & 0.73 \\
\hline$f_{c m, 28 d}(M P a)$ & 139.94 & 119.39 & 130.33 & 120.42 & 114.23 & 124.16 & 119.39 \\
\hline$f_{t}(M P a)$ & 9.49 & 7.61 & 9.41 & 9.59 & 7.32 & 7.25 & 7.39 \\
\hline$f_{t u}(M P a)$ & 6.83 & 6.28 & 6.80 & 9.90 & 6.3 & 5.26 & 5.07 \\
\hline$\varepsilon_{t u}(\% o)$ & 2.36 & 1.81 & 3.53 & 6.25 & 2.71 & 3.00 & 2.79 \\
\hline
\end{tabular}

From each mix, two couples of beams of size $100 \times 150 \times 750 \mathrm{~mm}^{3}$ were prepared to evaluate the selfhealing properties. Additionally, four cubes sized $100 \times 100 \times 100 \mathrm{~mm}^{3}$, and two prisms of size $100 \times 100 \times 500 \mathrm{~mm}^{3}$ were prepared to control the variation of properties between groups through compressive strength and flexural strength tests, respectively. All specimens were demolded 24 hours after mixing and were stored in a humidity chamber at $20^{\circ} \mathrm{C}$ and $95 \%$ relative humidity.

Compressive strength was tested on cubes at the age of 28 days following EN 12390-3, and the results are included in Table 1. The results show a slight decrease in the compressive strength in the mixes incorporating the self-healing admixture and the nanomaterials. In this latter case, this decrease can be caused by a slight increase in water content (3-12.5\%) to maintain the self-compacting properties of the mix. Despite the higher additional water introduced in those mixes with nanocellulose (C34 to C36), compressive strength in these mixes is not reduced further.

Additionally, the two prismatic $100 \times 100 \times 500 \mathrm{~mm}^{3}$ specimens were tested in four-point bending, and the tensile performance of each mix was evaluated following a simplified inverse analysis method [20], [21]. Table 1 shows the values obtained through this method, where the mixes with Penetron and ANF displayed a similar response comparable to the reference mix. 


\subsection{Self-healing methodology}

\subsubsection{Pre-cracking methodology}

To evaluate self-healing, $100 \times 150 \times 750 \mathrm{~mm}^{3}$ reinforced beams (Figure 2) were prepared. The reinforcement embedded in the beams consisted of $6 \varnothing 6$ stirrups and $2 ø 8$ lower reinforcing bars. Fourpoints bending test was performed with these beams following a setup with a central span of $600 \mathrm{~mm}$ for the bottom supports and $150 \mathrm{~mm}$ of the distance between the two loading points. Two rows of DEMEC points were glued at the middle span in order to control the strain variation at these two levels using a before, during, and after every loading-unloading cycle. Complementary, an Linear Variable Differential Transformer (LVDT) was placed at the bottom of the beam to register the loaddisplacement evolution. Additional information about the test performed can be read in a previous publication [22].
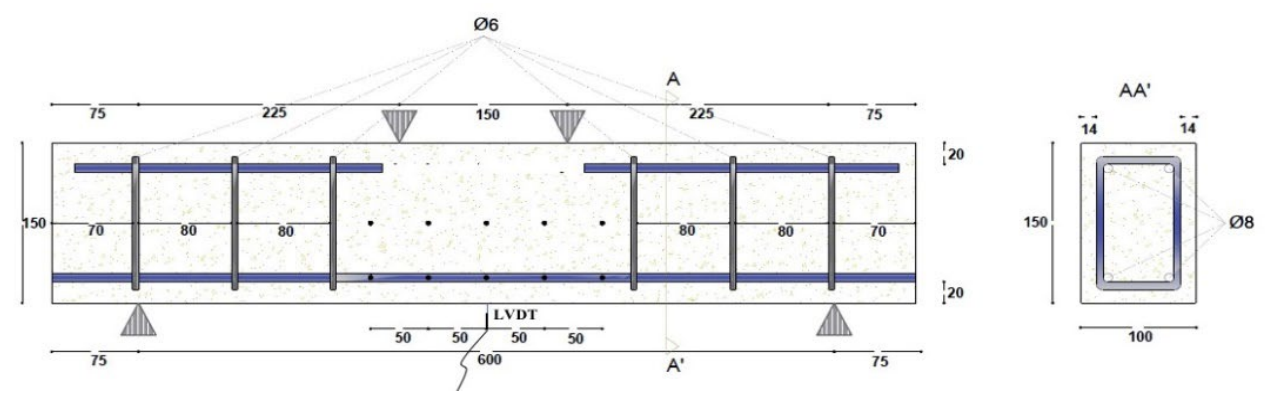

Figure 2. Reinforced Beam model and DEMEC point locations, sizes are in millimeters.

These beams were pre-cracked after 28 days of age, utilizing a four-point bending test. For this study, pre-cracking tests were divided into two levels of damage, named Low and High Strain levels:

- $\quad$ Low Strain (LS): strain on the lower DEMEC line of $0.5 \%$ during loading;

- $\quad$ High Strain (HS): residual strain between 1 and $2 \%$ after unloading, measured at the lower DEMEC row, a condition in which the rebars start to yield, beyond the service limit state.

Whereas for those beams damaged at the LS, the strain value was very controllable and the desired value was easy to reach, in those beams targeted to suffer high strain values, it was challenging to achieve the target residual strain, since the beam is working near its service limit, and thus, a small increase in load will produce enormous changes in the residual strain. Figure 3 shows an example of the load-displacement graphs obtained for the LS and HS levels.

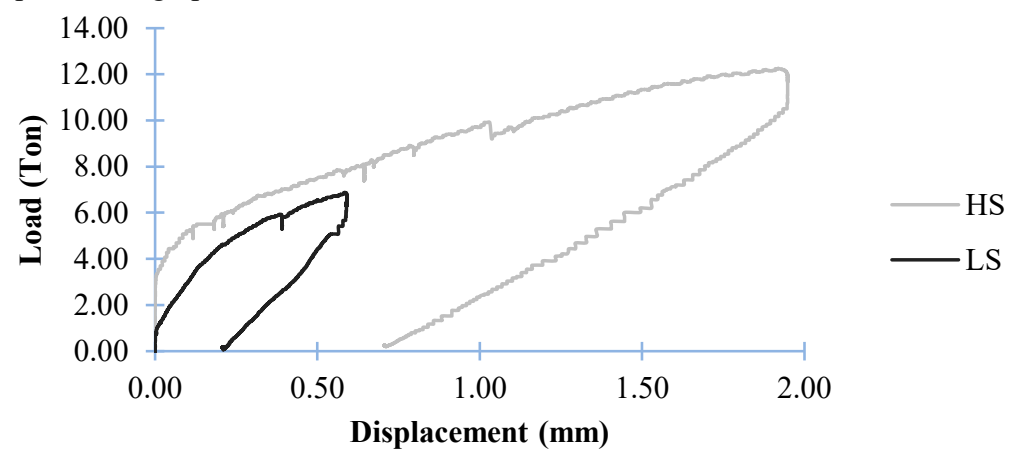

Figure 3. Load Displacement curves obtained for concrete type C3 during the pre-cracking stage of the beams for LS and HS damage levels. 


\subsubsection{Preparation of the healing samples}

After pre-cracking the beams, all the prisms were sawn in four smaller prisms $15 \times 15 \times 5 \mathrm{~cm}^{3}$ as indicated in Figure 4, since cracks are produced in the middle span of the beam. These samples were named A, $\mathrm{B}, \mathrm{C}, \mathrm{D}$, and were assumed to have the same deformation due to their location in the beam (Figure 2). Since the self-healing test performed in this work is destructive, samples " $A$ " were selected to evaluate the properties before self-healing and samples "B" after self-healing. Samples named C and D were used as extra samples to verify results when necessary.
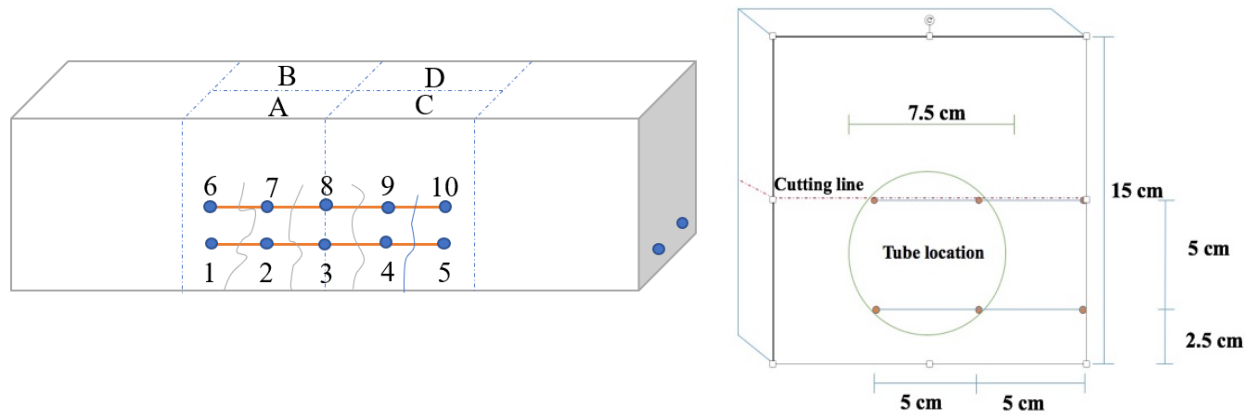

Figure 4. Diagram of the beam indicating the sawing lines to obtain the self-healing samples (left) and tube location for the water permeability test based on chloride penetration (right).

To promote self-healing reactions, complete water immersion in deionized water for 28 days was selected as the healing condition. Deionized water was selected to avoid any influence of the chlorides and calcium content of local tap water in the test.

\subsubsection{Crack analysis}

The crack size was measured in the sawed samples by using a PCE-MM200 microscope for the LS group and using a concrete crack-meter for the HS group with visible cracks. This quantification was performed at the two DEMEC lines. In this way, the crack properties (number, size) can be measured for the two lines and compared with the strain level obtained during (or after) the pre-cracking test.

It needs to be mentioned that, during these measurements, it was detected that some small cracks $(<0.05 \mathrm{~mm})$ were healed partially or even entirely before starting the healing conditions (Figure 5).
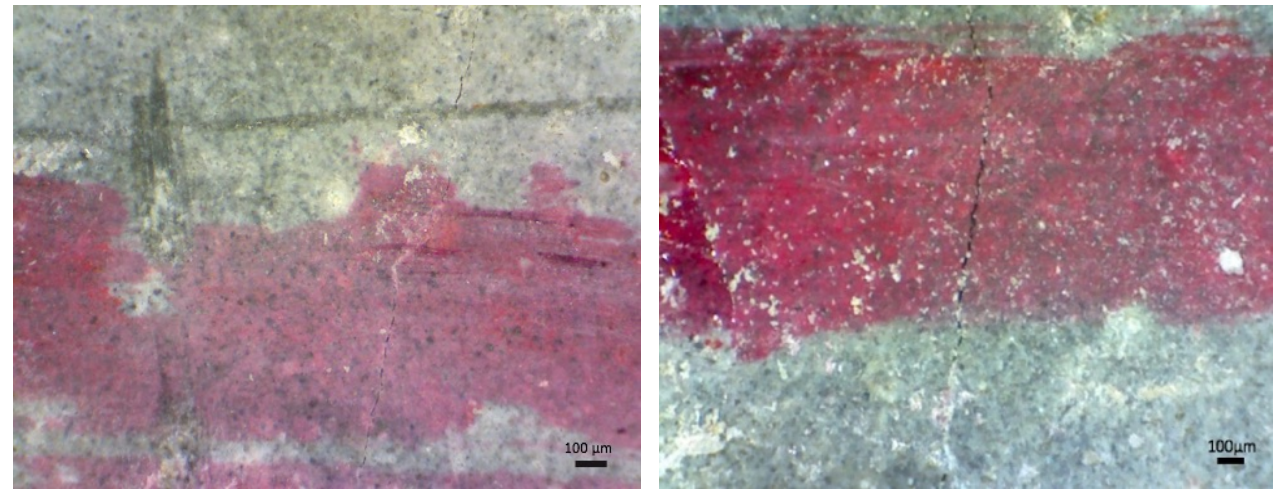

Figure 5. Partially healed cracks in beams that suffered low and high strain levels (left and right, respectively). 


\subsubsection{Modified water permeability test through chlorides penetration}

As detected in previous works [22], the water permeability of UHPFRC samples in cracked conditions was harder to evaluate since they were able to resist the high-pressure water permeability test, and water was not passing through their cracks. Because of that, a modified water permeability test was proposed, based on the use of sodium chloride and its reactivity to silver nitrate as an indicator to show the areas where water was able to penetrate.

This method consisted of using a PVC tube ( $\varnothing_{\mathrm{e}}=75 \mathrm{~mm}$, length around $60 \mathrm{~cm}$ ) glued to the specimens with a resin (in this case, Sikaflex $11 \mathrm{FC}$ ). This tube was filled with salt water with a concentration of $35 \mathrm{~g} \mathrm{NaCl} /$ liter, and the salted water column was left for 3 days over the samples. The water level was controlled every working day, so it remained around $50 \mathrm{~cm}$, and in case of visible evaporation, tap water was added to maintain the same pressure level. After three days, the tube was removed, and the specimen was cut transversely to the direction of the cracks with a circular saw for concrete following the diagram in Figure 4 right.

In order to measure the chloride penetration depth, first, specimens were left to dry, and afterwards, a silver nitrate $\left(\mathrm{AgNO}_{3}\right)$ solution with a concentration of $0.1 \mathrm{~mol} / \mathrm{l}$ was sprayed on both cracked surfaces where the cut was made. After the chemical reaction, the area colored in white is the area of interest, where silver ions reacted with the chloride ions, indicating the penetration.

The sections obtained were photographed using a digital camera to evaluate the differences between samples that healed during 28 days in deionized water and unhealed samples. These images were analyzed with photography software (Adobe Photoshop), binarized to black and white pixels (Figure 6 ), and the penetration of chlorides in the section was compared with the penetration in each section. With this method, cracks are detected, even if they are in the range of small microns. It has also been detected that, in some samples, the penetration of chlorides occurred not only through the crack but also through its porosity in the uncracked areas, $\mathrm{P}_{0}$ in Figure 6 . Generally, this penetration due to porosity is extremely low for UHPFRC, and thus, when evaluating the affected areas, most of the influence will come from the cracked areas.

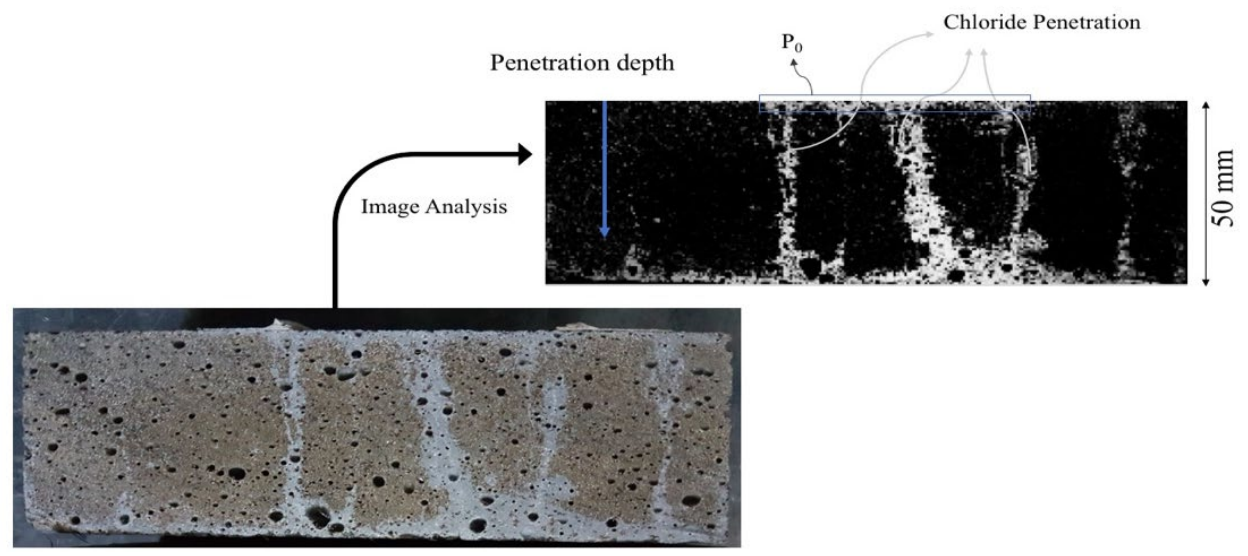

Figure 6. Result of image analysis performed on a section after the water permeability test based on chloride penetration. 


\section{EXPERIMENTAL RESULTS AND DISCUSSION}

\subsection{The relation between strain and crack width}

The average crack width obtained for each beam $\left(\omega_{\text {avg }}\right)$ was compared with the residual strain of the beam obtained at the upper and the lower DEMEC lines ( $\left.\varepsilon_{\text {avg }}\right)$ from the pre-cracking test.

Figure 7 shows the linear relation obtained between the residual strain and the average crack width, as measured in all the beams in the low and top DEMEC lines. As expected, those values obtained at the top DEMEC line were smaller in terms of crack width and terms of residual strain. It can be seen that strains lower than $0.5 \%$ produced cracks near $10 \mu \mathrm{m}$, and when increasing the strain, the crack size increased noticeably. The crack size in the HS is dispersed, while in the LS level, the crack size range remains limited. No significant differences were detected at this pre-cracking stage in the formation and size of the cracks depending on the presence of crystalline admixtures and nanomaterials.

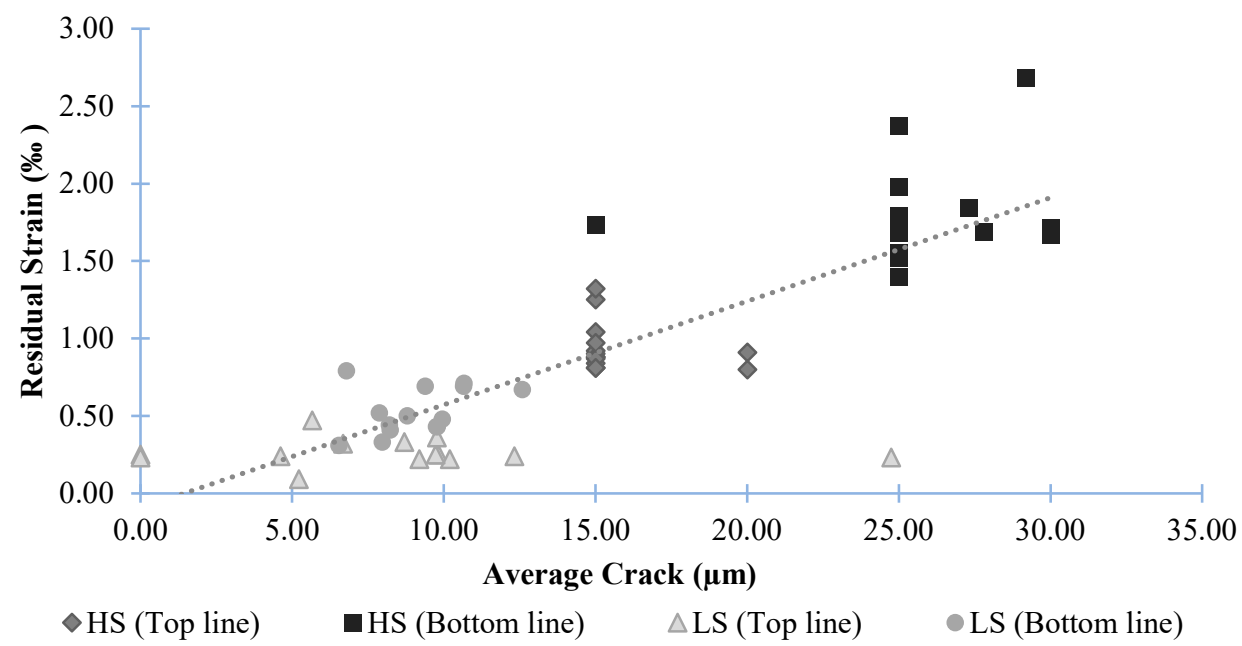

Figure 7. Comparison of the residual strain and the average crack width obtained in all the beams.

\subsection{Chloride penetration}

All the prisms after the cut were photographed before and after healing, and each photo was analyzed to evaluate the penetration of chlorides. Figure 8 shows four examples of the pictures obtained for the mix $\mathrm{C} 3$ after suffering the low or high strain levels, before and after healing.

Comparing both, the photos and the binarized pictures, in general, the healed samples presented lower penetration than the samples before healing. Additionally, the high strain specimens had larger and much clearer penetration areas than low strain specimens. However, several difficulties have been detected to evaluate the penetration in low strain specimens, and thus, the accuracy of this method should be discussed and improved. Furthermore, another difficulty of this method is that some samples can be contaminated during the wet-cut, depending on the human factor.

Despite these difficulties to quantify the penetration, the penetration results obtained in this work can be discussed for each case. For instance, control samples without self-healing admixtures (C3) partially healed at both low and high strain levels. This decrease of chloride penetration indicates that inside the cracked sample, chlorides are not able to penetrate deeper inside the matrix or this small penetration is not detectable with the methodology used in this work. This result is an evidence of the protection to the penetration of chlorides that autogenous healing is able to provide to UHPFRC structures. 


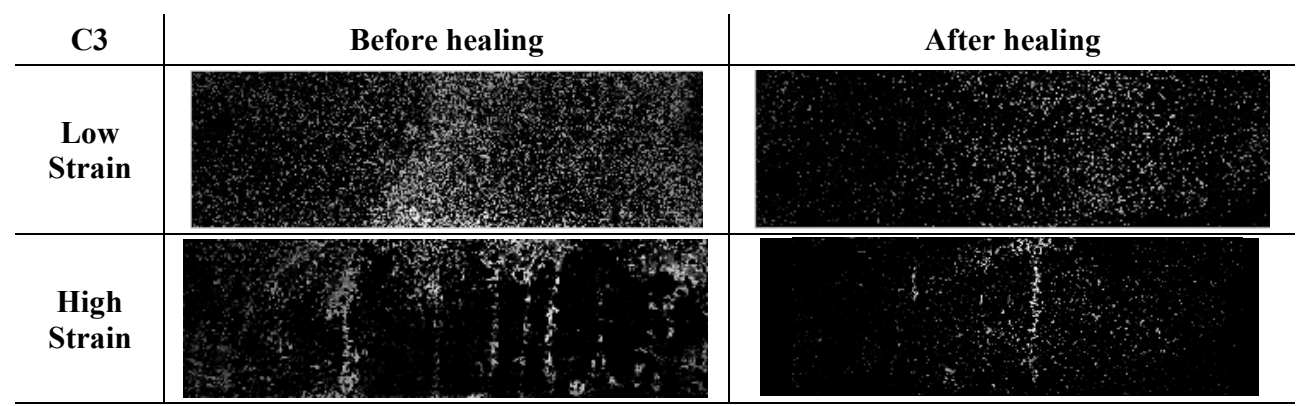

Figure 8. Comparison between chloride penetration in C3 samples that suffered low strain (top row) and high strain (bottom row) before and after healing.

Similarly, for C31 and C32, containing Penetron CA and CA plus ANF, the depth of penetration was reduced after healing when compared to the results before healing. In this case, except for one sample with higher crack width $(50 \mu \mathrm{m})$, which experienced only partial healing, the cracks were almost entirely healed and no penetration was detected after healing. However, in C33 samples, which also had CA plus ANF but with higher contents of CA, healing did not occur to the same extent, probably due to an excessive dosage of CA, obtaining larger depths of penetration.

In the case of mixes containing nanocellulose, $\mathrm{C} 34$ to $\mathrm{C} 36$, the results indicate that for $\mathrm{C} 34$ and $\mathrm{C} 35$ samples, for the small strain limit, self-healing was able to stop chloride penetration completely. However, for the high strain level, healing did not occur, but the depth of penetration was partially healed. In the case of $\mathrm{C} 36$, whereas the photos display potential healing, chloride penetration still occurred significantly in depth for both low and high strain limits.

The obtained qualitative results are consistant with those reported in the literature, showing the potential protection from chlorides penetration that autogenous and enhanced self-healing are able to produce in concrete [2], [7], [18]. However, this methododology needs further improvements to allow the exact quantification of the areas penetrated by chlorides, and will be the focus of future studies.

\section{CONCLUSIONS}

The conclusions that can be drawn from this study are:

- The pre-cracking method used allows obtaining different crack width ranges for the low and high strain level (around $10 \mu \mathrm{m}$ and $25-50 \mu \mathrm{m}$ respectively). For the low strain, crack widths increased gradually with the strain, however, when reaching the high strain levels, the crack size became more dispersed. No significant differences were detected in the formation and size of the cracks depending on the presence of crystalline admixtures and nanomaterials.

- The methodology followed allows a qualitative evaluation of self-healing and the results indicate that: 1) healed samples presented lower penetration than samples before healing, and 2) high strain specimens had larger and clearer penetration areas than low strain specimens. However, the accuracy of this methodology needs to be improved to allow the quantification of the penetration.

- Reference UHPFRC obtained partial healing after 28 days healing under deionized water, showing that autogenous healing in this concrete type for the size of cracks studied is able to provide some protection from the penetration of chlorides. Additionally, upgrading concrete to contain small dosages of CA and ANF improved the self-healing response, to obtain practically no penetration from the chlorides, even for those samples with large cracks $(25-50 \mu \mathrm{m})$. However, the presence of nanocellulose or an excessive use of CA of have been reported to not clearly improve, or even reduce the self-healing properties of this concrete. 


\section{ACKNOWLEDGEMENTS}

The authors would like to acknowledge the European Union's Horizon 2020 ReSHEALience project (Grant Agreement No. 760824).

\section{REFERENCES}

[1] D. Homma, H. Mihashi, and T. Nishiwaki, "Self-Healing Capability of Fibre Reinforced Cementitious Composites," J. Adv. Concr. Technol., vol. 7, no. 2, pp. 217-228, 2009.

[2] M. Maes, D. Snoeck, and N. De Belie, "Chloride penetration in cracked mortar and the influence of autogenous crack healing," Constr. Build. Mater., vol. 115, pp. 114-124, 2016.

[3] C. Edvardsen, Water permeability and autogenous healing of cracks in concrete, vol. 96. 1999.

[4] N. De Belie et al., "A Review of Self-Healing Concrete for Damage Management of Structures," Advanced Materials Interfaces, vol. 5, no. 17. 2018.

[5] H. L. Wang, J. G. Dai, X. Y. Sun, and X. L. Zhang, "Characteristics of concrete cracks and their influence on chloride penetration," Constr. Build. Mater., vol. 107, pp. 216-225, 2016.

[6] K. Wang, D. C. Jansen, S. P. Shah, and A. F. Karr, "Permeability study of cracked concrete," Cem. Concr. Res., 1997.

[7] B. Šavija and E. Schlangen, "Autogeneous healing and chloride ingress in cracked concrete," Heron, vol. 61, no. 1, pp. 15-32, 2016.

[8] M. Ismail, A. Toumi, R. François, and R. Gagné, "Effect of crack opening on the local diffusion of chloride in cracked mortar samples," Cem. Concr. Res., vol. 38, no. 8-9, pp. 1106$1111,2008$.

[9] K. Habel and P. Gauvreau, "Response of ultra-high performance fiber reinforced concrete (UHPFRC) to impact and static loading," Cem. Concr. Compos., vol. 30, no. 10, pp. 938-946, 2008.

[10] E. Denarié and E. Brühwiler, "Strain-hardening Ultra-high Performance Fibre Reinforced Concrete: Deformability versus Strength Optimization," Restor. Build. Monum., vol. 17, no. 6, pp. 397-410, 2014.

[11] S. Granger, G. Pijaudier-Cabot, and ALoukili, "Mechanical behavior of self-healed Ultra High Performance Concrete: From experimental evidence to modeling," Proc. 6th Int. Conf. Fract. Mech. Concr. Concr. Struct., vol. 3, pp. 1827-1834, 2007.

[12] P. Escoffres, C. Desmettre, and J. P. Charron, "Effect of a crystalline admixture on the selfhealing capability of high-performance fiber reinforced concretes in service conditions," Constr. Build. Mater., vol. 173, pp. 763-774, 2018.

[13] K. Sisomphon, O. Copuroglu, and E. A. B. Koenders, "Self-healing of surface cracks in mortars with expansive additive and crystalline additive," Cem. Concr. Compos., vol. 34, no. 4, pp. 566-574, 2012.

[14] M. Roig-Flores, S. Moscato, P. Serna, and L. Ferrara, "Self-healing capability of concrete with crystalline admixtures in different environments," Constr. Build. Mater., vol. 86, pp. 1-11, 2015.

[15] M. Roig-Flores, F. Pirritano, P. Serna, and L. Ferrara, "Effect of crystalline admixtures on the self-healing capability of early-age concrete studied by means of permeability and crack closing tests," Constr. Build. Mater., vol. 114, pp. 447-457, 2016.

[16] L. Ferrara, V. Krelani, and M. Carsana, "A 'fracture testing' based approach to assess crack healing of concrete with and without crystalline admixtures," Constr. Build. Mater., vol. 68, pp. 535-551, 2014. 
[17] L. Ferrara, V. Krelani, and F. Moretti, "On the use of crystalline admixtures in cement based construction materials: From porosity reducers to promoters of self healing," Smart Mater. Struct., vol. 25, no. 8, pp. 1-17, 2016.

[18] E. Cuenca, G. Cislaghi, M. Puricelli, and L. Ferrara, "Influence of self-healing stimulated via crystalline admixtures on chloride penetration," Am. Concr. Institute, ACI Spec. Publ., vol. 2018-June, no. SP 326, pp. 1-10, 2018.

[19] R. P. Borg, E. Cuenca, E. M. Gastaldo Brac, and L. Ferrara, "Crack sealing capacity in chloride-rich environments of mortars containing different cement substitutes and crystalline admixtures," J. Sustain. Cem. Mater., vol. 7, no. 3, pp. 141-159, 2018.

[20] J. Á. López, P. Serna, J. Navarro-Gregori, and E. Camacho, "An inverse analysis method based on deflection to curvature transformation to determine the tensile properties of UHPFRC," Mater. Struct. Constr., vol. 48, no. 11, pp. 3703-3718, 2015.

[21] J. Á. López, "Characterisation of the Tensile Behaviour of Uhpfrc By Means of Four-Point Bending Tests," no. March, 2017.

[22] A. Negrini, M. Roig-Flores, E. J. Mezquida-Alcaraz, L. Ferrara, and P. Serna, "Effect of crack pattern on the self-healing capability in traditional, HPC and UHPFRC concretes measured by water and chloride permeability," MATEC Web Conf., vol. 289, p. 01006, 2019. 